\begin{tabular}{|l|l|l|l|l|l|l|}
\hline InterteXto & Uberaba & UFTM & $\begin{array}{l}\text { v. 1 } \\
\text { n. } 2\end{array}$ & p. 35-61 & 2008 - jul. / dez. & ISSN 1981-0601 \\
\hline
\end{tabular}

\title{
O BAIRRO COMO ESPACIALIDADE DE INTIMIDADE COLETIVA EM DESVARIOS NO BROOKLYN, DE PAUL AUSTER
}

\author{
THE NEIGHBOURHOOD AS A SPACIALITY OF COLLECTIVE INTIMACY IN \\ THE BROOKLYN FOLLIES, BY PAUL AUSTER
}

Lilian Reichert Coelho ${ }^{1}$

\begin{abstract}
Resumo
Neste texto, apresentamos uma reflexão sobre as relações entre personagens e uma espacialidade específica, o bairro, compreendida, nos limites do romance analisado, Desvarios no Brooklyn, de Paul Auster, como topofilia. É no interior da referida espacialidade que as personagens conseguem resistir à opressão exercida de forma topofóbica por duas macro-espacialidades, a saber, a cidade de Nova York e o país, os Estados Unidos da América. A leitura apresentada neste estudo concentra-se na observação dos paradoxos inerentes à espacialidade topofílica configurada pelo bairro do Brooklyn - regida pelo eixo público-privado - e na dinâmica das topias instauradas pelas relações entre personagens e espacialidades.
\end{abstract}

Palavras-chave: espacialidade; positividade; bairro; literatura.

\begin{abstract}
In this text, we present a reflexion on the relashionship between characters and a specific spaciality, the neighbourhood. This relation is understood, inside the limits of the novel The Brooklyn Follies, by Paul Auster, as a positive space. Inside the referred spaciality, the characters can resist to a repression movement from two topophobic macro-spacialities, New York city and the country, the United States of America. The reading exposed above concentrates itself on the observation of the internal paradoxes of the positive spaciality represented by the Brooklyn neighbourhood - constructed through the public-private axis - and in the dynamics of the places raised by the observation of the relashionships between characters and spacialities.
\end{abstract}

Key-Words: spaciality; positivity; neighbourghood; literature.

O ponto de partida da presente reflexão concentra-se na observação de que personagens relacionam-se positiva e negativamente com espacialidades e lugares. A idéia positiva da espacialidade assume contornos enfáticos em Bachelard (1993), com a noção de topofilia, conceituada como "espaço feliz",

\footnotetext{
${ }^{1}$ Doutoranda pela Universidade Federal da Bahia. lilian reichert@yahoo.com.br
} 


\begin{tabular}{|l|l|l|l|l|l|l|}
\hline InterteXto & Uberaba & UFTM & $\begin{array}{l}\text { v. 1 } \\
\text { n. } 2\end{array}$ & p. 35-61 & 2008 - jul. / dez. & ISSN 1981-0601 \\
\hline
\end{tabular}

lugar de onde é possível defender-se das "forças adversas"; em suma, trata-se "dos espaços amados." (FERNANDES, 1992, p.19). Pelo termo, concebe-se a significação dos ambientes de aconchego e intimidade, pelo viés do imaginário, cuja tendência é o movimento para dentro. As topofilias constituem lugares privilegiados na construção da experiência pessoal e/ou coletiva. Na literatura de Paul Auster, observa-se a concepção de topofilias construídas como heterotopias, dentre as quais se destaca o bairro do Brooklyn.

Localizamos, na produção austeriana, interioridades relativas à intimidade partilhada, construída por laços afetivos cuja tessitura é traçada somente na e a despeito da megalópole. Assim mesmo, paradoxalmente. A espacialidade compartilhada compõe, na narrativa do romance Desvarios no Brooklyn (2005), de Paul Auster, eixo relativo ao espaço social, formado por tudo o que circunda as personagens no decurso da vida cotidiana. Dada a configuração positiva do bairro no romance, é legítimo afirmar que o Brooklyn constitui-se topofilia, no sentido atribuído por Bachelard (1993) como espaço de prazer. A leitura apresentada neste estudo aloja-se na observação dos paradoxos $^{2}$ inerentes à espacialidade referida - regida pelo eixo públicoprivado - e na dinâmica das topias instauradas pelas relações entre personagens e espacialidades.

Pelo termo topofilia, concebem-se os lugares de aconchego e intimidade, cuja tendência é o movimento para dentro. São espacialidades caracterizadas pelo sentido de habitação, tais como a casa e o quarto, de acordo com a argumentação sobre o imaginário formulada por Bachelard. Do

\footnotetext{
2 "O paradoxo é uma afirmação paralela à doxa: contradiz as percepções do conhecimento sensível e as opiniões do senso comum; por isso, complica o pensamento. O princípio aristotélico da não-contradição é fundamental para a doxa cotidiana: segundo ele, uma afirmação que contradiga a si mesmo não pode ser verdadeira. Mas o paradoxo costuma apresentar conclusão ou conseqüência contraditória: por incorporar a contradição na sua estrutura, torna-se difícil contestá-lo ou negá-lo. Os paradoxos não se podem classificar nem como falsos nem como verdadeiros." (BERNARDO: 2004, p.65-66). Nos limites desta reflexão, compreende-se a espacialidade do bairro como realidade paradoxal devido à configuração dupla exercida pelo Brooklyn: trata-se, simultaneamente, de espacialidade pública e privada, íntima e coletiva.
} 


\begin{tabular}{|l|l|l|l|l|l|l|}
\hline InterteXto & Uberaba & UFTM & $\begin{array}{l}\text { v. 1 } \\
\text { n. } 2\end{array}$ & p. 35-61 & 2008 - jul. / dez. & ISSN 1981-0601 \\
\hline
\end{tabular}

ponto de vista bachelardiano, trata-se de localizações privilegiadas no que concerne à acumulação da experiência pessoal, substrato da memória, das lembranças. No romance sob foco, o nome do sebo onde trabalham as personagens, Brightman's Attic, evidencia sentido negativo a uma das partes constitutivas da "casa". Ainda que falso, Brightman é o sobrenome do proprietário, Harry, e attic significa "sótão", lugar da "casa" onde, em geral, são alojados objetos desprezados. No caso, refere-se à morada dos livros antigos e ao escritório de Harry, personagem que tem muito a esconder sobre seu passado escuso. Em razão da pertinência da noção apresentada por Bachelard, mas na tentativa de ser fiel às especificidades da obra analisada, considera-se profícuo esgarçar a noção de topofilia da experiência de cunho exclusivamente individual para uma abordagem coletiva e social.

Cremos que tal expansão permite - e requer - a aproximação de pensadores das formas de socialidade contemporâneas como M. de Certeau, Z. Bauman e M. Maffesoli ${ }^{3}$, que apontam a necessidade de se observar, no contexto das grandes cidades, movimentos de (re)centramento, seja em localidades, seja em grupos ${ }^{4}$. Na dinâmica da configuração social contemporânea, o bairro institui - pela reunião na mesma espacialidade -, traços reconhecíveis como próprios do lugar, gerando, em alguns casos, modos de viver e "tipos" sociais peculiares. Embora nascido no Brooklyn, a personagem focal, Nathan Glass, vivera desde os três anos no subúrbio (em Bronxville), afastado do distrito nova-iorquino onde se desenvolvem as ações narradas. Desvarios no Brooklyn configura-se inicialmente como uma narrativa de retorno à origem, delineada pela (re)descoberta do lugar, tanto para o

\footnotetext{
${ }^{3}$ A relevância das contribuições de teóricos contemporâneos localizados no interior de áreas como Sociologia, Antropologia e Filosofia reside na assunção da impossibilidade de análise do espaço romanesco austeriano descolado da referencialidade, incisivamente convocada pelo escritor na produção em termos de espaço concreto, "real".

${ }^{4}$ Trata-se de leituras da vida urbana contemporânea e da observação de novas formas de socialidade pautadas pela instauração de alternativas às imposições da chamada "sociedade global", cujo vetor orienta-se por movimento centrípeto. Em contraponto, valorizam-se experiências centrífugas, pautadas por movimentos direcionados para 0 interior, que compreende o familiar, o microscópico.
} 


\begin{tabular}{|l|l|l|l|l|l|l|}
\hline InterteXto & Uberaba & UFTM & $\begin{array}{l}\text { v. 1 } \\
\text { n. } 2\end{array}$ & p. 35-61 & 2008 - jul. / dez. & ISSN 1981-0601 \\
\hline
\end{tabular}

narrador quanto para o leitor, que adentra ao lado de Nathan no bairro. A posição de desbravamento assumida pelo narrador nos momentos iniciais da narrativa é evidente, Nathan está em fase de identificação dos estabelecimentos comerciais, das ruas e, sobretudo, dos moradores do Brooklyn, vistos primeiramente "de fora", mas logo incorporados afetivamente pelo narrador, que passa a tratá-los com familiaridade, tornando-se depois um deles. Todo o percurso empreendido, do estranhamento inicial à familiaridade, é construído sob um viés positivo, ressaltando-se o pitoresco do lugar e a espontaneidade dos "brooklynianos".

O bairro constitui espacialidade urbana que propicia trocas humanas, “(...) lugar de uma passagem pelo outro, intocável porque distante, e no entanto [sic] passível de reconhecimento por sua relativa estabilidade. Nem íntimo, nem anônimo, vizinho." (CERTEAU, 1996, p. 43). A vizinhança e a estabilidade da vida e dos afetos apontam um tipo de construção espacial da experiência coletiva localizada no bairro pelo viés da dimensão tátil da vida - muito mais do que pelo olhar (que caracteriza a liminaridade, o voltar-se para o outro e não para dentro de si) - e da horizontalidade, ambas refletindo instauração e consolidação do contato interpessoal. Bairros, em geral, têm histórias, personagens, formas de relacionamento peculiares entre vizinhos, configurando-se como espacialidades de diferenciação no interior da cidade, constituindo - muitas vezes, especialmente no contexto da megalópole cidades quase autônomas, como é o caso do Brooklyn ${ }^{5}$ em relação a Nova York $^{6}$. Tatilidade e horizontalidade são eixos destacados pelo narrador de

\footnotetext{
${ }^{5}$ O Brooklyn caracteriza-se como um "distrito" de Nova York. Leão Barros explica que cada cidade pode compreender "bairro" de maneira própria e que, na configuração estadunidense, a noção de district é entendida como "referencial que se define precipuamente pelas relações de tipo secundário que se dão à sua escala." (2004, p. 4). Além de limite oficial, territorial, de organização do tecido citadino, o district é compreendido em razão da dimensão subjetiva e da memória coletiva.

${ }^{6}$ Até 1898, o Brooklyn constituía-se como cidade autônoma (fundada no final do século XVII), ano em que foi anexada à chamada Grande Nova York, tornando-se um de seus distritos. Além do Brooklyn, são distritos de Nova York: Bronx, Queens, Manhattan e Staten Island.
} 


\begin{tabular}{|l|l|l|l|l|l|l|}
\hline InterteXto & Uberaba & UFTM & $\begin{array}{l}\text { v. 1 } \\
\text { n. } 2\end{array}$ & p. 35-61 & 2008 - jul. / dez. & ISSN 1981-0601 \\
\hline
\end{tabular}

Desvarios no Brooklyn, pela ênfase na exposição das marcas diferenciais do bairro. Comprova-se o acento nas dimensões tátil e horizontal pela maneira como as relações humanas são construídas, salienta-se a falta de hierarquia entre as personagens, a ausência de maniqueísmos de qualquer espécie, a facilidade e a rapidez no florescimento de relações amorosas e de amizade. Tais elementos são atestados pelo narrador durante todo o desenrolar da narrativa, que celebra o bairro como topia fundamental e insubstituível na instauração das relações humanas. A felicidade e a satisfação por (re)encontrar um lugar como o Brooklyn são interpretadas pelo narrador como dádiva, oportunidade indispensável de ser feliz.

O tom - ou intensidade emocional - preferencial do narrador é o olhar sobre as características constitutivas do bairro pelo eixo do humor-cínico, sublinhado pela narração intra ${ }^{7}$ e homodiegética ${ }^{8}$. É pelo posicionamento do narrador que Auster explicita seu próprio olhar sobre os problemas típicos da contemporaneidade, expondo o caráter caótico e imprevisível da vida urbana cotidiana, representada pela espacialidade de Nova York e circunscrita aos problemas dos Estados Unidos da América. Vale ressaltar que, em Desvarios no Brooklyn, argumenta-se negativamente acerca dos encaminhamentos políticos do país e positivamente sobre o centramento na vida comunitária. A experiência comungada familiar resulta da conscientização dos indivíduosvizinhos no que tange à valorização dos afetos e da singularidade de experiências proporcionadas pela espacialidade íntima compartilhada.

Pode-se dizer que, para os moradores de um bairro, as espacialidades conhecidas e vivenciadas em regime de intimidade são constitutivas tanto da "alma" coletiva quanto da "alma" individual. Nessa perspectiva, observa-se que o sentimento das personagens relativo ao bairro do Brooklyn é homólogo aos

Informações disponíveis em: www.nyc.gov e www.brooklynonline.com acessados em 23 de novembro de 2007.

7 De acordo com Genette (s.d), trata-se de um dos posicionamentos possível no que diz respeito ao nível narrativo. O narrador enuncia de dentro da história.

${ }^{8} \mathrm{O}$ narrador está presente como personagem na história que conta (GENETTE: s/d, p. 244). 


\begin{tabular}{|l|l|l|l|l|l|l|}
\hline InterteXto & Uberaba & UFTM & $\begin{array}{l}\text { v. 1 } \\
\text { n. } 2\end{array}$ & p. 35-61 & 2008 - jul. / dez. & ISSN 1981-0601 \\
\hline
\end{tabular}

sentimentos sobre a casa. O bairro adquire feições de lar; trata-se da casa ampliada, correlação que permite a leitura da espacialidade amada constituída pelo bairro como microcosmo ${ }^{9}$, ponto diferencial positivo localizado no interior do macrocosmo devastador formado, em primeira instância, pela cidade (Nova York) e, em segunda, pelo país (os Estados Unidos da América). Como é possível observar, as duas espacialidades referidas são construídas por gradação; enquanto a cidade funciona como elemento externo ameaçador em relação à familiaridade interior proporcionada pelo bairro, o país figura como presença ubíqua, maligna e devastadora.

Maffesoli adverte que o "espaço vivido, vivenciado em comunidade" marca a configuração típica do contexto urbano contemporâneo. Em razão disso e da defesa da cidade como lugar propício ao estar-junto, considera-se legítima a aproximação do pensamento do filósofo à reflexão sobre o bairro do Brooklyn tal como exposta pelo narrador de Desvarios no Brooklyn. O bairro é construído na narrativa como espacialidade diferencial situada na grande cidade, com potencial instaurador de contatos interpessoais duradouros. $O$ argumento central do romance reside na possibilidade de articulação do relacionamento entre personagens e espacialidade à noção de "recentramento comunitário", identificada por Maffesoli como tendência da contemporaneidade. Tal movimento acontece tanto no campo territorial no sentido tradicional ${ }^{10}$

\footnotetext{
${ }^{9}$ Saliente-se que o termo é empregado no contexto desta reflexão sem conotações de caráter antropológico, segundo o qual, na perspectiva compreensiva de Douglas (2004, p. 140), “(...) é um sistema de símbolos no qual cada elemento do sistema diz respeito ao universo como totalidade. Assim, os elementos diversos relacionam-se um com o outro e dependem do sistema global que circunscreve sua significação. Um modelo unificado do mundo se repete em cada contexto." O ponto de vista adotado neste trabalho compreende a construção da espacialidade do Brooklyn por Paul Auster como heterotopia. Portanto, como um microcosmo (entendido como um mundo completo, menor em tamanho relativamente a um macrocosmo, constituído em primeiro grau pela cidade de Nova York, em segundo, pelo país). O bairro, compreendido como topofilia, constitui dissonância em relação ao macrocosmo, representado como distopia.

${ }^{10}$ Como todas as noções que fundamentam o discurso geográfico, a noção de território também é marcada pela falta de consenso. De qualquer maneira, na perspectiva geográfica, afirma-se que o espaço geográfico pré-existe ao território, o que significa que a atividade humana territorializa o espaço. A concepção de território em geral é carregada de sentidos políticos, sobretudo político-administrativos, o que explica sua usual correspondência com a
} 


\begin{tabular}{|l|l|l|l|l|l|l|}
\hline InterteXto & Uberaba & UFTM & $\begin{array}{l}\text { v. 1 } \\
\text { n. } 2\end{array}$ & p. 35-61 & 2008 - jul. / dez. & ISSN 1981-0601 \\
\hline
\end{tabular}

quanto em território simbólico (da experiência vivida e interpretada coletivamente). Este último é marcado pela evidência de que "o espaço que nos ocupa é um conjunto complexo constituído, ao mesmo tempo, pela materialidade das coisas (ruas, monumentos, tráfego) e pela imaterialidade das imagens de diversas ordens." (MAFFESOLI, 1996, p. 264). Isso equivale a dizer que elementos concretos coabitam o bairro em estreita relação com atribuições de sentido de ordem subjetiva.

O retorno de Nathan ao bairro de origem, o encontro com familiares queridos e a reabilitação da família evidenciam movimento de (re)centramento onde antes reinava a dispersão, experimentada tanto em termos espaciais quanto das relações familiares e afetivas. As personagens viviam em ambientes distintos e não mantinham comunicação, até a reunião ocorrida no Brooklyn, que as acolhe e permite a reconfiguração da família, acrescida de novos componentes. Com isso, o próprio bairro é interpretado e reinterpretado como lugar positivo por excelência, heterotopia de compensação em relação à isotopia figurada pela cidade de Nova York e até mesmo se comparado com o idílico interior do país, representado por Vermont.

Conforme apontado, Desvarios no Brooklyn apresenta como espacialidade isotópica a cidade de Nova York, marcada por temporalidade específica, momentos anteriores e imediatamente posteriores ao evento histórico de 11 de setembro de $2001^{11}$. O narrador é personagem-protagonista, Nathan Glass, sarcástico e prático vendedor de seguros de vida aposentado recém-recuperado de câncer pulmonar. Ao perceber a proximidade incontornável da velhice, Nathan trata a iminência do fim da vida de forma

concepção de território nacional, espaço físico onde se fixa a nação. Trata-se, portanto, de "um espaço onde se delimita uma ordem jurídica e política; espaço medido e marcado pela projeção do trabalho humano com suas linhas, limites e fronteiras" (BORDO; SILVA; NUNES; BARBOSA; MIRALHA: 2004).

11 O dia 11 de setembro de 2001 registrou a destruição dos dois edifícios que compunham o complexo comercial World Trade Center, conhecido como Torres Gêmeas, por dois aviões seqüestrados por fundamentalistas. 


\begin{tabular}{|l|l|l|l|l|l|l|}
\hline InterteXto & Uberaba & UFTM & $\begin{array}{l}\text { v. 1 } \\
\text { n. } 2\end{array}$ & p. 35-61 & 2008 - jul. / dez. & ISSN 1981-0601 \\
\hline
\end{tabular}

cínica, "Eu procurava um lugar sossegado para morrer. Um dia alguém me recomendou o Brooklyn, e já na manhã seguinte saí de Westchester e fui sondar o terreno." (AUSTER, 2005, p.7). O assumido cinismo do narrador reflete comportamentos típicos da contemporaneidade, que instaura 0 substrato para a figura do cínico como uma "figura de massa", isto é, um ser humano médio e não um outsider. Nathan Glass é um homem "normal" que, na posição de narrador, esforça-se no sentido de desqualificar-se o tempo todo como alguém pouco afeito ao convívio familiar e social. Isso se confirma pelo comportamento pregresso da personagem - péssimo pai e marido - mas se modifica pelas ações narradas, que conduzem o leitor à aposta interpretativa pelo eixo da redenção. De qualquer sorte, a escolha por um narrador social e moralmente "mediano" confirma a explicação de Sloterdijk sobre o fato de que "o anonimato torna-se um amplo espaço para o desvio cínico." (1984, p. 192). $\mathrm{O}$ posicionamento de Nathan perante si e a sociedade funciona consoante à figura do cínico, entendido como "(...) uma personagem não-socialmente integrada cuja profunda falta de ilusões é parelha à de qualquer hippie." (SLOTERDIJK, 1984, p. 192) ${ }^{12}$. Isso é o que o narrador pensa de si e o que informa no início, mas a narrativa demonstra que, a despeito de inúmeras características negativas, trata-se de um herói real e não ideal. As ações e decisões de Nathan tecem a trama que une todas as personagens por laços de benignidade, compaixão e amor. O narrador de Auster carrega, portanto, traços típicos do homem contemporâneo, dentre os quais se destaca o cinismo, conforme apontado. O cínico contemporâneo sente-se bem na cidade - pelo menos nos limites do bairro -, mesmo consciente dos problemas do ambiente urbano e do encaminhamento político do país.

Ao instalar-se no Brooklyn, o narrador reencontra por acaso o sobrinho Tom Wood, após oito anos sem contato. Nathan afirma que Tom é o herói da

\footnotetext{
${ }^{12}$ No original: "(...) anonymity now becomes the large space for the cynical deviation. The modern cynic is an integrated asocial character whose deep-seated lack of illusions is a match for that of any hippy." (SLOTERDIJK: 1984, p. 192).
} 


\begin{tabular}{|l|l|l|l|l|l|l|}
\hline InterteXto & Uberaba & UFTM & $\begin{array}{l}\text { v. 1 } \\
\text { n. } 2\end{array}$ & p. 35-61 & 2008 - jul. / dez. & ISSN 1981-0601 \\
\hline
\end{tabular}

narrativa, no entanto, o processo de leitura conduz o leitor a certificar-se de que o herói e personagem focal é o narrador. Nathan desilude-se com Tom, pelo fato de o sobrinho, que Ihe parecia um rapaz de futuro promissor, ter se transformado em vendedor de livros em um sebo. Significativo na caracterização psicológica e moral da personagem Tom é a paixão à distância pela B.M.P. - sigla inventada pelo rapaz para designar Nancy Mazzuchelli, habitante do Brooklyn, como "a Bela Mãe Perfeita". A caracterização de Tom está organicamente ligada à problematização geral apresentada pela narrativa, trata-se de um jovem (aos 30 anos) idealista, mas absolutamente pessimista. Observa-se que as personagens jovens de Desvarios no Brooklyn personificam toda a juventude, na perspectiva do narrador. Sete anos antes, Tom vira desmoronar a unidade da família, com a morte da mãe e a transformação da irmã, Aurora, de adolescente rebelde em atriz de filmes pornográficos. Na tentativa de auxiliar a irmã e a sobrinha (Lucy), Tom, quatro anos antes, desistira do doutorado em Literatura e, diante da configuração dos fatos e da projeção negativa quanto ao futuro - seu, da irmã, da família, do país transformara-se de jovem promissor em adulto decadente, de provável professor universitário em taxista e balconista de sebo. Assim são construídas as personagens jovens da família Glass-Wood de Desvarios no Brooklyn Tom e Aurora, como desistentes da vida.

Os nomes atuam significativamente na caracterização das personagens, embora da mesma família, Nathan tem por sobrenome "Glass" (vidro), enquanto Tom e Aurora são "Wood" (madeira). O termo "Glass" delineia-se diferentemente em relação à Trilogia de Nova York, neste, refere-se à cidade, qualificando-a; em Desvarios no Brooklyn, é nome próprio que, ao remeter às propriedades do material, contrapõe-se nitidamente a "wood". Glass diz respeito àquele de quem nada escapa, cuja percepção é translúcida e cuja constituição moral constrói-se pela ausência de alma, pelo cinismo.

Outro sentido convocado pelo sobrenome remete à idéia de fragilidade, homólogo à saúde de Nathan (em fase de recuperação de grave enfermidade), 


\begin{tabular}{|l|l|l|l|l|l|l|}
\hline InterteXto & Uberaba & UFTM & $\begin{array}{l}\text { v. 1 } \\
\text { n. } 2\end{array}$ & p. 35-61 & 2008 - jul. / dez. & ISSN 1981-0601 \\
\hline
\end{tabular}

contraponto do sobrinho, Tom Wood, cuja constituição física é tão forte quanto a maneira profundamente arraigada de pensar e vivenciar valores, conduzindose moralmente de forma exemplar, coerente e orientado por princípios nobres. Tom justifica a paixão à distância por Nancy Mazzuchelli não em termos de atração física, mas por deslumbramento sobre o suposto caráter exemplar da vizinha. O narrador instaura e reitera a nobreza de caráter de Tom durante a narrativa, embora não concorde com o sobrinho. Com isso, Nathan mantém a coerência dos caracteres, como cínico, embora preocupado com os rumos do país após as eleições presidenciais, prefere pensar em formas de viver e ser feliz enquanto estiver vivo, afinal, safara-se de quase fatal situação. Idealista, Tom preocupa-se com o destino do país, mas evita a ação, preferindo pensar em alternativas utópicas como evasão da realidade negativa.

A heterotopia criada por Auster em Desvarios no Brooklyn é marcada pela relação afetiva entre a espacialidade e os indivíduos que nela vivem e/ou circulam. A afetividade mantém-se de maneira eufórica devido à familiaridade existente entre as personagens e entre elas e o bairro do Brooklyn. No que diz respeito ao país, estabelece-se relação contrária, disfórica. Percebe-se intensa valorização de micro-espaços e micro-relações em detrimento de macroespaços e macro-relações, representadas pela cidade e, principalmente, pelo Estado $^{13}$, cuja presença ubíqua permeia toda a narrativa, inclusive textualmente, por debates entre as personagens acerca dos desdobramentos da eleição vindoura.

Quase todas as ações de Desvarios no Brooklyn acontecem no referido bairro de Nova York e, mesmo as que ocorrem em outras localidades, como a Carolina do Norte ou Vermont, têm desdobramentos ou originam-se na localidade nova-iorquina. É a espacialidade real de onde as personagens não conseguem fugir, tanto fisicamente (por distanciamento corporal) quanto pela constituição de laços afetivos rígidos. Ao pensar na possibilidade de evasão, as

\footnotetext{
${ }^{13}$ As eleições presidenciais futuras são tema de conversas entre as personagens, que temem a vitória de George W. Bush.
} 


\begin{tabular}{|l|l|l|l|l|l|l|}
\hline InterteXto & Uberaba & UFTM & $\begin{array}{l}\text { v. 1 } \\
\text { n. } 2\end{array}$ & p. 35-61 & 2008 - jul. / dez. & ISSN 1981-0601 \\
\hline
\end{tabular}

personagens criam coletivamente utopia localizada no interior do país, tratado - com ironia - como paraíso onde seria possível refugiarem-se da negatividade reinante no ambiente da megalópole. As espacialidades interioranas funcionam como utopia ${ }^{14}$ em relação à isotopia constituída pela cidade de Nova York. A utopia sonhada e compartilhada momentaneamente entre as personagens articula-se como "desvario" momentâneo e irrealizável, mas, na viagem ao interior, deparam-se com possibilidade efetiva de estabelecimento da comunidade ideal. É válido afirmar que, no final, utopia permanece com a carga semântica habitual, configurando-se mais como "sonho de liberdade" do que como realização.

As personagens devaneiam sobre um lugar utópico, no sentido tanto de Virilio quanto de Foucault. "A utopia é um lugar", afirma Virilio (2001, p.2), ao contrário de Foucault, para quem utopia é "posicionamento sem lugar real" (2006, p.414). As personagens do romance de Auster idealizam um lugar onde possam escapar das agruras da vida na sociedade estadunidense. O capítulo intitulado Uma noite de comes e bebes (p.107-119) condensa reflexão sobre a existência de um lugar ideal pela própria materialidade discursiva, pois aparece como peça teatral, rompendo momentaneamente a discursividade até então utilizada. A rubrica inicial registra,

Sábado à noite. 27 de maio de 2000. Um restaurante francês na rua Smith, no Brooklyn. Na parte de trás do salão, ao redor de uma mesa situada no canto esquerdo, reúnem-se três homens, Harry Brightman (ex-Dunkel), Tom Wood e Nathan Glass. (...) De cenário, já basta. Depois de iniciada a conversa, serão muito poucas as rubricas. É opinião do autor que, para a

\footnotetext{
${ }^{14}$ Noções de lugares imaginários contrapostos à realidade eram comuns desde a Antigüidade. Em A República, Platão apresenta uma das primeiras propostas de um lugar irreal, no caso, a cidade ideal. A utopia de Platão foi revisitada por outros pensadores ao longo do tempo como Santo Agostinho. Note-se que, em geral, as utopias, lugares ideais, estão situadas em terrenos o mais possível afastados do mundo "real", percebido pelo viés da negatividade, em função da constatação de injustiças sociais. Afirma-se veementemente essa distância pela separação física nítida da sociedade em que se vive: a llha de Utopia (de Thomas Morus) e a Nova Atlântida (de Francis Bacon) são ladeadas por água, enquanto Campanella localiza a Cidade do Sol numa longínqua planície. Utopias dos mais variados matizes reaparecem ao longo do tempo, reconfigurando-se ao sabor das contingências, até a contemporaneidade.
} 


\begin{tabular}{|l|l|l|l|l|l|l|}
\hline InterteXto & Uberaba & UFTM & $\begin{array}{l}\text { v. 1 } \\
\text { n. } 2\end{array}$ & p. 35-61 & 2008 - jul. / dez. & ISSN 1981-0601 \\
\hline
\end{tabular}

narrativa, importam apenas as palavras ditas pelas personagens acima citadas. (AUSTER, 2005, p.107).

Este capítulo é emblemático porque é o único em que três personagens conversam sobre o tema "política nacional", todas revelando tendências pessimistas, críticas e desesperançadas. Tom pretende "cair fora". Nathan traduz para Harry o descontentamento de Tom, a utopia seria "um lugar onde seja possível viver a vida segundo nossos próprios termos. (...) 'Édens Imaginários' revisitados. Mas para poder ir para lá é preciso se dispor a rejeitar a sociedade." (AUSTER, 2005, p.109). A expressão "Édens Imaginários" remete ao título de monografia defendida por Tom anos antes, daí a ironia de Nathan, cujos movimentos são orientados no sentido de fazer Tom retomar posicionamento otimista em relação à vida. Nesse esforço e empenhado na definição do lugar utópico para onde fugir da realidade negativa, Nathan propõe a idéia de "refúgio interior", sinônimo da mente, "lugar para onde um homem vai quando a vida no mundo real não parece mais ser possível" (AUSTER, 2005, p.110). Harry entende e revela que, quando garoto, no contexto da Segunda Guerra Mundial, inventara um lugar imaginário chamado "Hotel Existência".

A idéia de localização da utopia em um hotel instaura paradoxo, a possibilidade de concretização do sonho coletivo, concomitantemente acompanhada da impossibilidade de realização, pois a utopia situa-se em lugar de passagem, impessoal, sem laços, como "realidade do trânsito" (AUGÉ, 2005, p. 98). Harry conta que, mais tarde, já adolescente, imaginara outro "Hotel Existência", algum lugar no interior da Europa onde iria abrigar crianças perdidas. Adulto, a utopia transforma-se consideravelmente, fundando-se não mais no sonho ingênuo, mas em estereótipos cinematográficos, o que se coaduna com o caráter da personagem, cínico como o narrador - embora ingênuo -, sobretudo no que concerne à concepção da cidade.

Além da mente, Tom localiza a utopia em lugar concreto, "algum lugar do interior", em uma espécie de comuna socialista. Apartar-se definitivamente do mundo constitui, no entanto, possibilidade não-realizável no contexto 


\begin{tabular}{|l|l|l|l|l|l|l|}
\hline InterteXto & Uberaba & UFTM & $\begin{array}{l}\text { v. 1 } \\
\text { n. } 2\end{array}$ & p. 35-61 & 2008 - jul. / dez. & ISSN 1981-0601 \\
\hline
\end{tabular}

contemporâneo. Não há mudança efetiva de lugar, a heterotopia constituída pelo bairro vence o desejo das personagens, que permanecem no Brooklyn e tentam ser felizes, apesar dos acontecimentos propiciados pelas ingerências do poder político representado pela distopia caracterizada pelo país. Pela observação das produções austerianas, conclui-se que o escritor dificilmente permitiria que as personagens localizassem a felicidade ou o escape da vida urbana em lugar ideal(izado). Auster posiciona-se de forma demasiado realista face às questões políticas para propor utopias de qualquer espécie; da mesma maneira parecem pensar e agir as personagens de Desvarios no Brooklyn, narrativa que se descortina em relação direta ao episódio histórico de 11 de setembro de 2001. Trata-se de uma ode ao paradoxo, à vida urbana, intensa e confusa, regida pelo estabelecimento de limites e, concomitantemente, à vida comunitária, preponderantemente orientada por laços de proximidade.

Observa-se que, para as personagens de Desvarios no Brooklyn, a literatura também constitui utopia, possibilidade de suporte emocional frente à negatividade imposta pela configuração sócio-política. Isso se revela na estrada, onde Tom libera-se eloqüentemente, aviva-se ao dissertar sobre literatura - Joyce, Flaubert, Melville, Milton, Marlowe e seus favoritos, Hawthorne, Poe e Kafka. Após expor anedota biográfica a respeito de Kafka, Tom ressalta, "(...) quando a pessoa tem sorte suficiente de viver dentro de uma história, de viver dentro de um mundo imaginário, as dores deste mundo somem. Pelo tempo que durar a história, a realidade deixa de existir." (AUSTER, 2005, p. 168-169). A afirmação transcrita condensa a compreensão do narrador no que tange à função da literatura, propor a reflexão sobre a realidade e, ao mesmo tempo, possibilitar evasão temporária da negatividade do mundo.

A fim de esquecer os sofrimentos ocasionados pela enfermidade recémcurada, Nathan Glass torna-se uma espécie de escritor. O livro, porém, é pensado como informalidade, sem pretensões artísticas, tão "desvairado" quanto a vida pregressa do narrador e as histórias com que se depara no 


\begin{tabular}{|l|l|l|l|l|l|l|}
\hline InterteXto & Uberaba & UFTM & $\begin{array}{l}\text { v. 1 } \\
\text { n. } 2\end{array}$ & p. 35-61 & 2008 - jul. / dez. & ISSN 1981-0601 \\
\hline
\end{tabular}

Brooklyn. A obra de Nathan recebe o título de "O livro dos desvarios humanos". Nele, o narrador-personagem prefere abordar, além de histórias próprias, deslizes de outros homens também. A autodesqualificação de Nathan como escritor é evidente na maneira como apresenta e justifica a existência do projeto ficcional em processo de construção,

Chamei esse projeto de livro, mas na verdade de livro ele não tinha nada. (...) eu estava juntando o que no fundo era uma coleção de notas ao acaso, uma mistureba de anedotas desconexas que eu ia jogando numa caixa de papelão. Havia muito pouco método em minha loucura. Algumas histórias não tinham mais que duas linhas de texto e várias delas, sobretudo os disparates, as batatadas e os trocadilhos involuntários de que eu tanto gostava, limitavam-se a duas ou três palavras. (AUSTER, 2005, p.12).

A reflexão sobre literatura reincide no episódio em que Nathan, Tom e Lucy ${ }^{15}$ empreendem viagem rumo ao norte para conduzir a menina à casa de Pamela, parente distante. Tom e Nathan, convencidos da incapacidade de cuidar da criança, decidem levá-la a uma casa "de família". No caminho, desenrola-se discussão sobre literatura, exercício metalingüístico freqüente na produção de Auster, ainda que, em Desvarios no Brooklyn, a reflexão sobre o fazer literário esteja subsumida se comparada a outros escritos - como $A$ Trilogia de Nova York (2003), Leviatã (2001), A noite do oráculo (2004) e Viagens no Scriptorium (2007) - e em relação ao questionamento político. É significativo o fato de a referida discussão acontecer de forma eloqüente na espacialidade da estrada, portanto, em situação de deslocamento ${ }^{16}$ das personagens. É na fluidez do percurso e não na fixidez de lugar bem marcado que a literatura aparece explicitamente no texto. Paradoxalmente, o tema configura-se como a pele do discurso, no que ele tem de mais e de menos aparente ao mesmo tempo.

\footnotetext{
${ }^{15}$ Criança, filha de Aurora, irmã de Tom e sobrinha de Nathan, que aparece misteriosamente no Brooklyn.

${ }^{16}$ A estrada constitui um não-lugar, na proposta de Marc Augé; posicionamento de passagem, para Foucault.
} 


\begin{tabular}{|l|l|l|l|l|l|l|}
\hline InterteXto & Uberaba & UFTM & $\begin{array}{l}\text { v. 1 } \\
\text { n. } 2\end{array}$ & p. 35-61 & 2008 - jul. / dez. & ISSN 1981-0601 \\
\hline
\end{tabular}

A reflexão centra-se no diálogo entre política e literatura, esta compreendida não apenas como instituição social. A literatura é personificada, o que se observa pela apresentação de dados concretos, detalhados, da vida de personalidades reais e paradoxais como Poe e Thoreau. A personagem Tom, especialista em literatura, afirma,

Eles ocupam pólos opostos do pensamento americano. Mas é justamente aí que está a beleza da coisa. Um bêbado do Sul reacionário em sua visão política, aristocrático em suas maneiras, fantasmagórico em sua imaginação. E um abstêmio do Norte - radical em suas opiniões, puritano em seu comportamento, perceptivo em seu trabalho. Poe era artifício, penumbra de aposentos à meia-noite. Thoreau era simplicidade, luminosidade da vida ao ar livre. (AUSTER, 2005, p.21).

O exercício auto-reflexivo é convocado para apresentar a literatura como discurso em processo, o que lhe permite auto-enfrentamento e posicionamento combativo face à sociedade, como tenta realizar Auster na trilha de Poe e Thoreau. A relação com escritores do passado permite reconhecer a instauração da idéia de passagem do tempo marcada pelo sentido de filiação (de Auster via a personagem Tom) e de inconclusão no que concerne aos sentimentos sobre a pátria.

A negatividade tem como contraponto a figura do "Hotel Existência" de Tom, cuja materialização ocorre, de certa forma, durante a incursão ao interior, pela pousada onde são obrigados a pernoitar, Chowder $\operatorname{lnn}{ }^{17}$. Trata-se de uma pousada desativada, pertencente a Stanley Chowder, que recebe ajuda da única filha, Honey Chowder, futura senhora Tom Wood. A utopia concretiza-se apenas temporariamente (embora se irradie permanentemente na narrativa, pela união de Tom e Honey) nesse lugar idílico, próximo da natureza, onde o

\footnotetext{
17 Conforme nota do tradutor, chowder significa "uma espécie de caldeirada de frutos do mar" (AUSTER: 2005, p. 177). O Longman Dictionary of English Language and Culture define chowder como: "a thick soup prepared from bits of fish and other sea animals (shellfish), vegetables, meat and often milk." (1992, p. 213). Trata-se, portanto, de prato similar às brasileiras moqueca e mariscada.
} 


\begin{tabular}{|l|l|l|l|l|l|l|}
\hline InterteXto & Uberaba & UFTM & $\begin{array}{l}\text { v. 1 } \\
\text { n. } 2\end{array}$ & p. 35-61 & 2008 - jul. / dez. & ISSN 1981-0601 \\
\hline
\end{tabular}

mundo parece suspenso e em perfeita harmonia. As personagens valorizam por breve tempo a vida campestre, distante da negatividade da megalópole, mas o poder de atração do Brooklyn é mais incisivo, mesmo com todos os problemas e com a iminência de tragédia de amplas proporções, morte de Harry, mal-estar de Nathan e o evento de 11 de setembro.

$\mathrm{Na}$ passagem das personagens pelo interior do país, Nathan expõe preconceitos bilaterais, dos interioranos em relação aos moradores de grandes cidades e vice-versa. O preconceito é reiterado constantemente, mas, devido à adoção de perspectiva positiva, prevalece possibilidade de convivência harmônica. As boas relações são construídas pelas figuras do futuro sogro de Tom (Stanley Chowder) e dos mecânicos Al Sênior e Al Júnior, que consertam o carro de Nathan. De qualquer forma, é no interior que se potencializa a realização da utopia. A pousada dos Chowder é concebida pelas personagens Nathan e Tom como vislumbre de concretização do Hotel Existência, logo revelada impossível pelo anúncio telefônico sobre a morte de Harry e pela imposição do Brooklyn como locus preferencial da experiência efetiva.

Pelo exposto, observa-se que o Brooklyn constitui a heterotopia preferencial no romance Desvarios no Brooklyn, a despeito da tangência de realização da utopia. O bairro é construído pelo recurso da metonimização do universo em localidade específica, próxima e, ao mesmo tempo, diáfana. Além de constituir-se como heterotopia de compensação, o Brooklyn pode ser interpretado também como heterotopia de desvio ${ }^{18}$, pois abriga seres humanos moralmente repreensíveis do ponto de vista puritano característico da sociedade estadunidense, Harry (falsário, golpista, traidor), Tom (jovem que tinha tudo para dar certo, mas desistiu sendo, portanto, caracterizado como fraco), Nathan (incapaz de lidar com a ex-mulher e a filha, além da rejeição inicial à idéia de cuidar da menina Lucy) e Aurora (rebelde, ex-pin-up, exusuária de drogas, facilmente conduzida por opiniões alheias). Além disso,

${ }^{18}$ Constitui heterotopia de desvio a espacialidade "(...) na qual se localiza os indivíduos cujo comportamento desvia em relação à média ou à norma exigida." (FOUCAULT: 2006, p.416). 


\begin{tabular}{|l|l|l|l|l|l|l|}
\hline InterteXto & Uberaba & UFTM & $\begin{array}{l}\text { v. 1 } \\
\text { n. } 2\end{array}$ & p. 35-61 & 2008 - jul. / dez. & ISSN 1981-0601 \\
\hline
\end{tabular}

configura-se como desvio - ainda que positivo - em relação à dinâmica imposta pela isotopia representada pela cidade de Nova York. O Brooklyn também é apresentado como espaço-temporalidade, configurando heterotopia de tempo ou heterocronia, mais especificamente, a "(...) do tempo que se acumula infinitamente." (FOUCAULT, 2006, p.419). O bairro articula passado e presente. Trata-se da espacialidade onde ações relativas à vida ordinária desenrolam-se linearmente, mas o passado é constantemente evocado, sobretudo na relação ao macro-espaço distópico, os Estados Unidos da América.

Várias temporalidades podem coabitar a cidade como um todo, mas a expressão de entrelaçamento efetivo das vivências humanas verifica-se de modo mais próximo e afetuoso nos bairros. Antônio Candido confirma o caráter subjetivo e compartilhado do bairro, ao afirmar que, "(...) além de determinado território, o bairro se caracteriza por um segundo elemento, o 'sentimento de localidade' existente nos seus moradores (...)" (1987, p. 57-65). A localidade constituída pelo bairro é formada pelo conjunto de ruas que têm em comum a proximidade espacial - das próprias ruas e das pessoas - e uma memória constituída historicamente. Lefebvre salienta nuanças - positivas e negativas a respeito das ruas. Do ponto de vista positivo, o filósofo defende não se tratar "simplesmente de um lugar de passagem e circulação" (1999, p.29). Nessa perspectiva, pode-se afirmar que, na dinâmica da cidade, a rua constitui topia primordial do encontro, pois "nela efetua-se o movimento, a mistura, sem os quais não há vida urbana, mas separação, segregação estipulada e imobilizada." (LEFEBVRE, 1999, p.29-30). O argumento negativo reside no fato de a rua constituir-se como lugar dos encontros superficiais, casuais, que não se caracterizam, efetivamente, como encontros.

Na perspectiva do narrador de Desvarios no Brooklyn, as ruas do bairro amado e compartilhado constituem-se pelo viés exclusivo da positividade, dos encontros saborosos que propiciam relacionamentos duradouros, regidos pela acumulação de experiências. Paralelamente à acumulação, há, no romance, o 


\begin{tabular}{|l|l|l|l|l|l|l|}
\hline InterteXto & Uberaba & UFTM & $\begin{array}{l}\text { v. 1 } \\
\text { n. } 2\end{array}$ & p. 35-61 & 2008 - jul. / dez. & ISSN 1981-0601 \\
\hline
\end{tabular}

apelo a relações de heterocronia, baseadas "no que ele [o tempo] tem de mais fútil, de mais passageiro, de mais precário, e isso sob a forma da festa." (FOUCAULT, 2006, p.419). No Brooklyn atravessado pelo olhar de Nathan Glass, estabelecimentos comerciais exercem posicionamentos heterotópicos, como o diner Cosmic e o restaurante francês onde as personagens conversam sobre via utópica contra as agruras do mundo hostil. Paradoxalmente à idéia de acumulação, inclusive de tempo, permitido por tais heterocronias, é legítimo afirmar que lugares desse tipo constituem espacialidades de passagem, porém não no sentido fluido das estradas. Trata-se de lugares regidos pela contingência, onde não se permanece por muito tempo, mas aos quais sempre se pode retornar a fim de exercer atividade específica e vital, como comer, beber ou conversar, diferentemente da estrada.

O bairro caracteriza-se também pela heterotopia de aberturafechamento, revelando, entretanto, assimetria pela preponderância do pólo de abertura. Todos podem entrar no Brooklyn, transitar; todavia, para fazer parte dele, é preciso mais do que simplesmente chegar e instalar-se. Quem pretende habitar o bairro deve ser aprovado em espécie de "rito de purificação", inclusive o narrador. No capítulo inicial, intitulado "Prelúdio", Nathan, recém-recuperado da doença, sozinho, em vizinhança desconhecida, em apartamento novo, acolhe o conselho da filha, Rachel, segundo a qual é preciso distrair-se com alguma atividade prazerosa. Sem perspectivas, o convalescente decide escrever "O livro dos desvarios humanos", "Não era meu desejo desnudar a alma ou mergulhar em introspecções sombrias. O tom seria leve e cômico do princípio ao fim e meu único objetivo era me manter entretido, empregando nisso o máximo de horas que me fosse possível." (AUSTER, 2005, p. 12). Pela correlação entre procedimentos no livro escrito pela personagem e Desvarios no Brooklyn, observa-se movimento metalingüístico. O narrador expõe "por dentro" a arquitetura do livro que se lê - narrado por voz homodiegética - por intermédio do artifício constituído pela escritura de outro livro no interior do romance. O caráter metalingüístico evidencia-se no início do segundo capítulo, 


\begin{tabular}{|l|l|l|l|l|l|l|}
\hline InterteXto & Uberaba & UFTM & $\begin{array}{l}\text { v. 1 } \\
\text { n. } 2\end{array}$ & p. 35-61 & 2008 - jul. / dez. & ISSN 1981-0601 \\
\hline
\end{tabular}

quando o próprio narrador afirma, "Eu venho papagueando há umas dez, doze páginas já, mas meu propósito foi o de me apresentar ao leitor e montar 0 cenário para a história que estou prestes a contar." (AUSTER, 2005, p. 18). A instância narradora introduz a personagem central, o herói do livro, seu sobrinho Tom Wood. Embora não queira assumir o posto, o que se harmoniza com a reiterada performance de autodesqualificação, Nathan é o herói do romance. Ele alinhava as relações entre as outras personagens, mostrandoIhes que há possibilidade de construir vida nova, o que só pode acontecer no ambiente do bairro do Brooklyn.

Nathan encontra Tom no Brooklyn por acaso. Este reencontro é fundamental para o desenvolvimento de toda a narrativa, alicerçada em encontros e reencontros orientados na direção do processo de reconstituição familiar. O lugar do reencontro também é fundamental, um sebo, abrigo de livros antigos, pouco freqüentado. Trata-se de um lugar semifechado, semipúblico, onde o inesperado impera, dada a dimensão pública, qualquer pessoa pode entrar e tudo pode acontecer, conforme comprova a narrativa.

Nathan apresenta Tom ao leitor a partir de suas próprias expectativas, criadas no passado, sobre o futuro profissional do sobrinho, o penúltimo encontro fora por ocasião da formatura de Tom, rapaz inteligente, promissor. A imagem e os feitos do passado contrastam com a figura de Tom no presente, de doutorando em Literatura, o rapaz passara a balconista de um sebo, movimento consideravelmente decrescente na perspectiva do narrador. $O$ narrador surpreende-se no contato inicial com o sobrinho, cuja derrocada revela-se evidente em todos os âmbitos, físico, econômico, profissional, emocional. De atlético, o sobrinho passara a gordo; de feliz, a solitário e infeliz; de otimista, tornara-se pessimista, transformações interpretadas pelo narrador como diretamente motivadas por desencontros familiares e pela má condução política do país.

Vale apontar que, apesar do parentesco entre narrador e personagens, estas são apresentadas sem pieguice ou dramaticidade, portanto, em 


\begin{tabular}{|l|l|l|l|l|l|l|}
\hline InterteXto & Uberaba & UFTM & $\begin{array}{l}\text { v. 1 } \\
\text { n. } 2\end{array}$ & p. 35-61 & 2008 - jul. / dez. & ISSN 1981-0601 \\
\hline
\end{tabular}

coerência com o estilo da narração. Embora assustado com o que vê após anos de separação, Nathan não se permite conduzir pela compaixão gratuita, mas se sente imbuído da obrigação de ajudar as personagens jovens a reestruturar suas vidas, no que é bem-sucedido. Inicialmente, Nathan não tem objetivo na vida; recuperado de um câncer, procura uma atividade para passar o tempo e "um lugar sossegado para morrer" (AUSTER, 2005, p. 7). Ao reencontrar os sobrinhos, percebe ainda ter papel relevante a cumprir e, caso empreenda movimento exitoso, antevê a própria redenção, pois fracassara como pai e marido no passado.

A despeito do cinismo de Nathan, Desvarios no Brooklyn configura-se como narrativa de múltiplas redenções, de homens e mulheres, jovens e idosos, sobretudo pela presença e ação fundamentais do narradorpersonagem. Viver no Brooklyn e afirmá-lo como lugar privilegiado para a construção de vida nova instaura perspectiva redentora para as personagens. O bairro é entidade viva, tanto quanto as personagens, por isso passível de reconstrução, de auto-regeneração, elemento portador da criação de vida tranqüila, a despeito da ameaça relativa ao futuro político do país. As personagens jovens, notadamente Tom e Honey, desprezam a administração Bush e temem a vitória do Partido Republicano nas iminentes eleições. A maneira sombria como são interpretadas as eleições coaduna-se com eventos pertencentes à narrativa, o mal-estar e a internação hospitalar de Nathan. Ao final, o narrador-personagem recupera-se, agradece pela existência e pela possibilidade de redenção, mas a felicidade está prestes a ruir, como se depreende da antecipação - em minutos - acerca dos ataques ao WTC, que Nathan apenas informa, a fim de prolongar um pouco mais a atmosfera de positividade reinante. $\mathrm{O}$ clima estabelece perfeita homologia com o estado de espírito do narrador, "E então eles me deram alta. Fazia uma manhã muito fresca e me senti tão feliz de estar vivo que a vontade era de gritar. Lá no alto, o céu estava azul, azul. Azul de brigadeiro." (AUSTER, 2005, p. 323). 


\begin{tabular}{|l|l|l|l|l|l|l|}
\hline InterteXto & Uberaba & UFTM & $\begin{array}{l}\text { v. 1 } \\
\text { n. } 2\end{array}$ & p. 35-61 & 2008 - jul. / dez. & ISSN 1981-0601 \\
\hline
\end{tabular}

Característica recorrentemente atribuída ao bairro pela instância narradora é o caráter de contraposição da localidade à idéia de "alma" estadunidense, não apenas à espacialidade opressora composta por Nova York, mas ao pensamento e à condução política do país. A informalidade do bairro, a instauração de relações afetivas estáveis e as surpresas da vida cotidiana oferecem compensação, adquirida na espacialidade desarranjada, informal, contrariamente à espacialidade macrocósmica, pretensamente ordenada. No Brooklyn, deve-se ser capaz de pensar e cometer os atos mais esdrúxulos no cotidiano, como fizeram Nathan e Joyce, Tom e Honey, Aurora e Nancy, Harry e Rufus. É pela perspectiva da personagem criança, Lucy, intermediada pelo narrador, que se observa o caráter de livre acesso propiciado pela espacialidade do referido bairro.

Consideramos fundamental relacionar ao romance a noção de ponto alto, proposta por Maffesoli. Por intermédio da referida concepção, reflete-se sobre a existência de espacialidades cuja função é promover a "comunicaçãocomunhão" entre os moradores de um lugar "emocionalmente vivido" como o bairro. Embora Maffesoli caracterize a própria megalópole como um ponto alto, dada sua leitura otimista da urbanidade contemporânea, na produção austeriana é evidente a inscrição do bairro do Brooklyn como ponto alto emblemático, em contraposição à distopia formada pela cidade e pelo país. É no bairro e não na cidade ou no país que a socialidade torna-se nítida e portadora de valores afetivos, enquanto o país constitui a espacialidade negativamente rígida e onipresente, portanto distópica, contra a qual o Brooklyn se opõe.

A espacialidade comunitária construída por Auster caracteriza-se pela apresentação do Brooklyn como um mundo particular, heterotopia de compensação ${ }^{19}$. Em que pese esse fato, sublinhe-se que o mundo percebido e

\footnotetext{
${ }^{19}$ Constituem heterotopias de compensação as espacialidades que criam "um outro espaço real, tão perfeito, tão meticuloso, tão bem-arrumado quanto o nosso é desorganizado, maldisposto e confuso" (FOUCAULT: 2006, p.420-421).
} 


\begin{tabular}{|l|l|l|l|l|l|l|}
\hline InterteXto & Uberaba & UFTM & $\begin{array}{l}\text { v. 1 } \\
\text { n. } 2\end{array}$ & p. 35-61 & 2008 - jul. / dez. & ISSN 1981-0601 \\
\hline
\end{tabular}

construído não exclui as referencialidades Nova York e Estados Unidos da América. O Brooklyn austeriano articula-se em termos de heterotopia de fechamento pela atividade de condensação do universo urbano contemporâneo, marcado, porém, pela ênfase nas especificidades positivas do bairro. Com isso, não se pretende negar que existam heterogeneidades, pelo contrário, o romance confirma o Brooklyn como espacialidade agregadora de diferenças, étnicas, etárias, comportamentais, culinárias, dentre outras. A fim de compreender melhor a complexidade dessas relações, considera-se pertinente observar as noções de "espaço doméstico" e de "banalidade do cotidiano", propostas por Maffesoli.

É pela leitura do bairro como espacialidade doméstica, ao mesmo tempo íntima e coletiva, que elementos - em geral objetos - aparentemente banais desempenham funções de ligação entre indivíduo e comunidade ${ }^{20}$. Espacialidades e objetos atuam no sentido de promover o enaltecimento da esfera doméstica, mesmo que a domesticidade seja construída na dimensão do espaço público, a rua ou uma casa comercial de fluxo intenso de pessoas. Em geral, o traço do doméstico é entendido como restrito ao espaço privado familiar no sentido burguês ${ }^{21}$-, o que Maffesoli tenta desconstruir sob o viés do paradoxo. No sebo, Harry Brightman emprega um jovem negro, jamaicano, portador de HIV, transformista, chamado Rufus Sprague (ou Tina Hott, nome artístico). No restaurante onde Nathan costuma almoçar, sozinho ou com Tom depois do reencontro, trabalha uma jovem garçonete hispânica, Marina

\footnotetext{
${ }^{20}$ Nos filmes Sem Fôlego e Cortina de Fumaça, ambos roteirizados por Paul Auster, a figura do cigarro exerce esse papel: o objeto estabelece ligações afetivas entre os indivíduos e entre as pessoas e o bairro do Brooklyn. O afeto não é construído em qualquer lugar, mas em estabelecimento comercial (tabacaria) situado em uma esquina. A esquina constitui espacialidade emblemática, pois está ligada à idéia de encruzilhada, cuja carga simbólica agrega sentidos de abertura, de possibilidades de escolha.

${ }^{21}$ Benjamin reflete sobre o espaço privado como instituição burguesa nos seguintes moldes: "Desde Luís Felipe, a burguesia se empenha em buscar uma compensação pelo desaparecimento de vestígios da vida privada na cidade grande. Busca-a entre quatro paredes. É como se fosse questão de honra não deixar se perder nos séculos, se não o rastro dos seus dias na Terra, ao menos o dos seus artigos de consumo e acessórios. Sem descanso, tira o molde de uma multidão de objetos (...)." (1994, p.43).
} 


\begin{tabular}{|l|l|l|l|l|l|l|}
\hline InterteXto & Uberaba & UFTM & $\begin{array}{l}\text { v. 1 } \\
\text { n. } 2\end{array}$ & p. 35-61 & 2008 - jul. / dez. & ISSN 1981-0601 \\
\hline
\end{tabular}

González, por quem o velho Nathan nutre paixão não-correspondida. Ao fim, Nathan encontra companheira, Joyce Mazzucchelli, viúva descendente de italianos moradora do Brooklyn. A domesticidade é criada também pela maneira de narrar de Nathan, percebe-se o encadeamento de clichês que correspondem à idéia sobre o estadunidense médio.

É em universo pluricultural que se movimentam as personagens de Desvarios no Brooklyn. O paradoxo instala-se pelo fato de que a diversidade de línguas, de origens, de culturas - poderia ser empecilho à harmonia, porém, a diferença instaura confiança e amizade, propiciada por encontros ocorridos em estabelecimentos comerciais, lugares de relações em geral efêmeras e marcadas pelo distanciamento. No Brooklyn, até mesmo os lugares públicos ou semipúblicos assumem caráter privado, propiciando relações de intimidade peculiares ao bairro.

Para além dos lugares propícios, o sentido de domesticidade é criado pela figura da família Mazzuchelli, antiga moradora do bairro. Nathan aborda a história do Brooklyn mesclada à história da família Mazzuchelli, representantes legítimos dessa categoria antropológica específica, denominada pelo narrador como "brooklynianos". A relação provoca homologia entre o bairro e os moradores, configurando-se com ênfase a constituição da espacialidade experimentada coletivamente como personagem focal da narrativa. Sobre a familiaridade e o caráter de abrigo de indivíduos "médios", o narrador explica que o bairro fora composto por "operários até meados dos anos de 1960, já que a conversão do Brooklyn a região habitada pela classe média só teve início por volta dos anos 70 (...)." (AUSTER, 2005, p.94). Inclui-se na domesticidade o "sotaque" específico do Brooklyn, ressaltado com veemência pelo narrador.

Aliada ao doméstico, a "experiência banal" constitui fator estruturante do que Maffesoli denomina "socialidade", definida pela positiva absorção de aspectos desprezados na lógica racional moderna, a saber, o lúdico, o imaginário, o emocional, o acaso, o paradoxo. O banal aparece como elemento básico no processo de valorização dos "pequenos fatos da vida cotidiana que, 


\begin{tabular}{|l|l|l|l|l|l|l|}
\hline InterteXto & Uberaba & UFTM & $\begin{array}{l}\text { v. 1 } \\
\text { n. } 2\end{array}$ & p. 35-61 & 2008 - jul. / dez. & ISSN 1981-0601 \\
\hline
\end{tabular}

por sedimentação, constituem o fundamento incontornável das maneiras de ser." (MAFFESOLI, 1996, p. 106). Por esse pensamento, deixa-se de acentuar valores considerados nobres pela lógica burguesa, tais como, moral, teleologia e racionalidade, suplantados por, amoralidade das personagens, ênfase em elementos aparentemente insignificantes, caráter "anedótico" da narração, afetividade, que regem a vida cotidiana contemporânea. Assume-se o cotidiano como aspecto fundamental da vida pela proximidade, mais do que as práticas das instituições tradicionais, distanciadas, para as quais os indivíduos constituem-se meros números, dados estatísticos.

A reflexão de Maffesoli ressalta o caráter gregário da vivência contemporânea, diferentemente da dispersão típica da massa ${ }^{22}$, fenômeno resultante de imposições da modernidade industrial. Agregar-se é compartilhar experiências comuns, como fazem as personagens que vivem no - e transitam pelo - Brooklyn construído por Auster. Divertem-se juntas, brigam, compartilham a memória por meio de vivência marcada pela "banalidade microscópica" (MAFFESOLI, 1996, p. 116) que rege a vida, a trivialidade, a localidade, o encantamento com o mundo, mesmo com tristezas, suplantadas pela solidariedade entre aqueles que dividem a mesma e amada espacialidade. Como sombra, no entanto, o macrocosmo caracterizado pelo país ameaça o universo microscópico, em movimento paradoxal, positividade e negatividade constituem eixos indissociáveis na construção da figura do bairro em Desvarios no Brooklyn. Mesmo acentuando-se a positividade, não há como negar o fato

\footnotetext{
${ }^{22}$ No ambiente das chamadas Teorias da Comunicação (BLUMER: 1978, p. 177-186), atribuise o nome de massa a um mesmo comportamento executado por indivíduos sem qualquer traço comum, dispersos no espaço, anônimos, sem laços de qualquer espécie. $O$ comportamento de massa é fugaz, não persiste no tempo; sua marca é, em dada circunstância, caracterizada pela atração individual por determinado objeto (um produto a partir da campanha publicitária, um candidato a partir da campanha política etc.). Os indivíduos, movidos por linhas individuais de ação e pensamento, executam a mesma ação (compram um produto ou votam em um candidato), mas sem articulação alguma, embora formem, em razão exclusiva da ação desempenhada, uma homogeneidade. No comportamento de massa inexiste a possibilidade de reunião de indivíduos formando um grupo, como acontece com a multidão.
} 


\begin{tabular}{|l|l|l|l|l|l|l|}
\hline InterteXto & Uberaba & UFTM & $\begin{array}{l}\text { v. 1 } \\
\text { n. } 2\end{array}$ & p. 35-61 & 2008 - jul. / dez. & ISSN 1981-0601 \\
\hline
\end{tabular}

de que o bairro está contido na negatividade do universo composto pela cidade e pelo país e é por ela ameaçado.

Nathan Glass nascera no Brooklyn, de onde mudara cedo. Trata-se, portanto, de uma narrativa de retorno, de reabilitação bem-sucedida, relativa ao indivíduo que acumulou experiências e retorna ao lugar conhecido e acolhedor, nem que seja orientado inicialmente por perspectiva negativa, "(...) procurava um lugar sossegado para morrer." (AUSTER, 2005, p.7). A vida de rusgas com a ex-mulher e com a filha, Rachel, é suplantada pela agitação de encontros inesperados e envolvimento em histórias mirabolantes proporcionadas pela nova vida no Brooklyn ${ }^{23}$. A atmosfera geral do romance é de positividade, de esperança, "um hino à vida normal" (AUSTER, 2007, p.19). Todas as personagens deparam-se com a perspectiva de vida nova, fértil e feliz, apesar do que o futuro encerra e que tremeluz no tecido romanesco de Auster, temese a vitória de George W. Bush nas eleições de 2000, o que, de fato, acontece, acentuando o cinismo demonstrado por Nathan e a desilusão de Tom. As personagens parecem prever que o resultado da eleição trará algo de extremamente maléfico, como se observa ao final do livro, com a referência ao fato não-ficcional do ataque ao WTC, em Nova York, pelo qual Bush é responsabilizado. Como desforra à negatividade, os trechos finais do livro apontam textualmente para a reflexão celebrativa sobre a "sorte e uma satisfação" que é "viver" (AUSTER, 2007, p.19).

A convocação explícita do terrível acontecimento histórico, não-ficcional, reitera a atribuição do caráter distópico da cidade e do país em relação ao bairro, heterotopia compensadora da negatividade pela instauração da

\footnotetext{
${ }^{23}$ Não raro a literatura de Auster apresenta personagens centrais, em geral homens, que se recuperam de uma doença ou da perda de familiares, como em $A$ noite do oráculo e $O$ livro das ilusões, respectivamente. Eles encontram um motivo para viver assumindo novos papéis e, às vezes, novas identidades. Com Nathan Glass não é diferente, embora não haja efetiva troca de identidade: vendedor de seguros de vida aposentado, pai e marido fracassado, ele se assume como um pseudo-escritor, um pseudo-pai e um pseudo-avô.
} 


\begin{tabular}{|l|l|l|l|l|l|l|}
\hline InterteXto & Uberaba & UFTM & $\begin{array}{l}\text { v. 1 } \\
\text { n. } 2\end{array}$ & p. 35-61 & 2008 - jul. / dez. & ISSN 1981-0601 \\
\hline
\end{tabular}

possibilidade de mútuo regozijo, mesmo localizando-se em meio a uma espacialidade regida por negatividade e ameaça.

A presença de várias personagens femininas e da criança (Lucy) conferem tom lúdico ao universo apresentado, pois elas "salvam" os homens, impedindo-os de desistir da vida. Não do suicídio, pelo qual, inclusive, Auster mostra-se em geral pouco afeito, mas da desistência da vida social e de recusa à sociedade. A leitura pelo viés simbólico é inevitável, pois a recorrência a personagens femininas instaura sentidos ligados às noções de fertilidade e vida, associadas ao feminino como atributo não apenas físico, mas como poder. Incertezas da vida cotidiana e melindres do relacionamento com mulheres, sejam irmãs, mães, filhas, sobrinhas, drag queens ou lésbicas, auxiliam na suavização do clima de terror inspirado pelas eleições presidenciais e pelos deslizes governamentais, instaurando sentimento geral de esperança, apesar de tudo.

\section{Referências}

AUGÉ, Marc. Não-lugares, introdução a uma antropologia da supermodernidade. 5.ed. Campinas, SP, Papirus, 2005.

AUSTER, Paul. Desvarios no Brooklyn.Trad, Beth Vieira. São Paulo, Companhia das Letras, 2005.

BACHELARD, Gaston. A poética do espaço. São Paulo, Martins Fontes, 1993.

BAKHTIN, Mikhail. O autor e a personagem na atividade estética. In Estética da criação verbal. 4.ed. São Paulo, Martins Fontes, 2003.

HUCITEC, 1988.

Questões de literatura e estética (A Teoria do Romance). São Paulo,

BAUMAN, Zygmunt. Modernidade líquida. Rio de Janeiro, Jorge Zahar, 2001.

BLUMER, Herbert. A massa, o público e a opinião pública. In COHN, Gabriel (org.). Comunicação e indústria cultural, leituras de análise dos meios de comunicação na sociedade contemporânea e das manifestações da opinião pública, propaganda e cultura de massa nessa sociedade. São Paulo, editora Nacional, 1978. (p.177-186)

BORDO A. A.; SILVA, C. H. P.; NUNES, M.; BARBOSA, T.; MIRALHA, W. Diferentes abordagens do conceito de território. São Paulo, FCT-UNESP, 2004. CANDIDO, Antonio. O discurso e a cidade. 3.ed. Rio de Janeiro, Ouro sobre Azul; São Paulo, Duas Cidades, 2004.

CERTEAU, Michel de. A Invenção do Cotidiano. $2^{a}$ ed. Petropólis, Vozes, 1996. 


\begin{tabular}{|l|l|l|l|l|l|l|}
\hline InterteXto & Uberaba & UFTM & $\begin{array}{l}\text { v. 1 } \\
\text { n. } 2\end{array}$ & p. 35-61 & 2008 - jul. / dez. & ISSN 1981-0601 \\
\hline
\end{tabular}

GENETTE, Gerard. Discurso da narrativa. Lisboa, Vega Universidade, s/d.

FERNANDES, António Teixeira. Espaço social e suas representações. Comunicação apresentada ao VI Colóquio Ibérico de Geografia, Porto, 14 a 17 de setembro de 1992. disponível em, http,ler.letras.up.pt acessado em 05 de dezembro de 2007.

FOUCAULT, Michel. Distância, aspecto, origem. In, Ditos e Escritos III. Estética, literatura e pintura, música e cinema. 2.ed. Rio de Janeiro, Forense Universitária, 2006.

Outros espaços. In, Ditos e Escritos III. Estética, literatura e pintura, música e cinema. 2.ed. Rio de Janeiro, Forense Universitária, 2006.

LEFEBVRE, Henri. A revolução urbana. Belo Horizonte, editora da UFMG, 1999

LONGMAN DICTIONARY ENGLISH OF LANGUAGE AND CULTURE. Essex, England, OTS, 1992.

MAIA, João. Michel Maffesoli e a cidade partilhada. In Revista FAMECOS, Porto Alegre (RS), n.26, abril de 2005.

MAFFESOLI, Michel. No fundo das aparências. 2.ed. Petrópolis, RJ, Vozes, 1996.

SLOTERDJK, Peter. Cynicism - the twilight of false consciousness. In NGC 33, 1984, p. 190-206.

TUAN, Yi-Tu. Topofilia - um estudo da percepção, atitudes e valores do meio ambiente. São Paulo, Rio de Janeiro, Difel, 1980.

VILAS BOAS, Gonçalo. Utopias, distopias e heterotopias na literatura de expressão alemã. In Cadernos de Literatura Comparada 6-7, Utopias. Orgs. Fátima Vieira e Jorge Miguel Bastos da Silva. Porto, Granito-Instituto de Literatura Comparada Margarida Losa, 2002. pp. 95-118.

VIRILIO, Paul. Da política do pior ao melhor das utopias e à globalização do terror. Revista FAMECOS. Porto Alegre, RS, n. 16, dezembro de 2001, p. 7-18. www.nyc.gov acessado em 23 de novembro de 2007.

www.brooklynonline.com acessado em 23 de novembro de 2007. 